\title{
Uma experiência de práticas educativas no currículo do curso de licenciatura em Educação Física
}

\author{
Jairo Antônio da Paixão*
}

\begin{abstract}
Resumo
O presente artigo busca relatar os resultados de uma experiência envolvendo práticas educativas no âmbito do currículo de formação inicial de professores de Educação Física. A proposta surgiu a partir da contradição percebida entre teoria e prática no trato com as diferentes concepções metodológicas para o ensino da Educação Física na disciplina Didática da Educação Física. Buscou-se, a partir das vivências nas aulas de Educação Física numa escola da rede publica municipal da cidade Ouro Preto, MG, não somente a articulação entre teoria e prática, como também, a partir das reflexões compartilhadas com o grupo de trabalho, inúmeras possibilidades de ação pedagógica no trato dos conteúdos da Educação Física em situações concretas com alunos e professores reais no cotidiano escolar.

Palavras-chave: Prática educativa, Educação Física, escola.
\end{abstract}

\section{Experience of educational practices in the curriculum of graduation course of Physical Education}

\begin{abstract}
This article aims to report an experience of educational practices in the curriculum of graduation course of physical education. The proposal arose from the contradiction perceived between theory and practice in dealing with different methodological concepts for teaching physical education in the discipline of didactic. We sought from the experiences in physical education classes in a public school in Ouro Preto, MG. It was possible not only the articulation between theory and practice, but also from shared with the working group reflections, numerous possibilities pedagogical action in dealing with the content of physical education in practical situations with real students and teachers in school routine.

Keywords: Educational practice, Physical Education, school.
\end{abstract}

\section{Introdução}

O presente texto relata os resultados de uma experiência envolvendo práticas pedagógicas no âmbito do currículo de formação inicial de professores de Educação Física. Trata-se de uma experiência que possibilitou aos acadêmicos do curso ampliar as perspectivas compreensivas da formação inicial, tomando, como ponto de partida, o fazer educativo balizado por subsídios formativos no campo da Didática e Metodologia do Ensino numa vertente crítica e transformadora da Educação Física enquanto componente curricular da educação básica (KUNZ; TREBELS, 2006; NEIRA; NUNES, 2009). Sobretudo, trata-se de uma vertente que concebe a Educação Física como uma prática pedagógica que trata de temas advindos da Cultura Corporal de Movimento, tendo como principal finalidade introduzir e integrar os alunos nessa ambiência, contribuindo no processo de formação dos cidadãos que irão reproduzir, produzir, transformar e partilhar as manifestações corporais que caracterizam essa área do saber (DARIDO, 2008).

\section{O cenário da Educação Física na escola}

No processo de construção histórica da
Educação Física é possível identificar que, desde a época em que se deu a sua inserção na escola, enquanto componente curricular - século XIX, em 1851, Reforma Couto Ferraz (DARIDO, 2008) -, vem sendo utilizada para os mais diferentes propósitos, como também, desviada completamente de suas finalidades juntamente com as demais disciplinas que compõem o currículo dos segmentos que compõem a educação básica.

Nessa direção, nota-se que as discussões que envolvem os contextos e cenários sociais em que decorre a formação inicial em Educação Física sempre mereceram destaque e preocupação no âmbito acadêmico brasileiro. No entanto, tais discussões ganharam maiores proporções, especialmente, nas duas últimas décadas em função de eventos como: vigência da atual LDB - Lei n. 9.394/96 (BRASIL, 1996); a instituição da Lei n. 9.696/98 (BRASIL, 1998), que dispõe sobre a regulamentação da profissão em Educação Física; e a instituição das Diretrizes Curriculares Nacionais para os cursos de Educação Física por meio da Resolução CNE/CES n. 7/2004, que foi precedida por polêmicas até a sua aprovação em 2004 (BRASIL, 2004).

No epicentro desses debates e discussões sempre esteve presente a dicotomia existente entre licenciatura e bacharelado, principalmente no que

*Endereço eletrônico: jairopaixao2004@yahoo.com.br 
concerne às atribuições e competências específicas ligadas aos respectivos campos de intervenções.

Ainda que licenciatura e bacharelado em Educação Física se configurem como campos distintos de intervenção, percebe-se, na maioria dos cursos de formação inicial, uma matriz curricular muito próxima, variando poucas disciplinas entre uma habilitação e outra, o que poderia levar a crer em mesmo perfil profissional, mesmas competências e um mesmo tipo de intervenção (SILVA, 2011). O autor acrescenta que essa situação demonstra a dificuldade por parte das instituições formadoras em definir perfis profissionais dos seus cursos que efetivamente traduzam as singularidades entre a licenciatura e o bacharelado.

$\mathrm{Na}$ escola, a Educação Física se configura de maneira diferenciada, haja vista sua especificidade como área do saber que tem como objeto de estudo o movimento humano mediatizado pelas diferentes práticas corporais e culturais e, com isso, a alegria, a descontração e, acima de tudo, o prazer vivenciado por uma parcela significativa de alunos no seu decurso. Como contraponto, por vezes, essa mesma especificidade leva a interpretações equivocadas sobre a Educação Física, tanto por parte dos alunos quanto pelos próprios professores com formação na referida área, chegando, em alguns casos, a ser percebida exclusivamente como atividade prática, com ênfase no aspecto técnico e tático de modalidades esportivas (DARIDO; RANGEL, 2005) e, em outros casos, meros momentos de lazer em que o aluno se encontra totalmente livre para fazer o que desejar (BARBOSA, 2001). Somada a isso está a falta de incentivos para o trabalho na escola, como a existência de estrutura física e materiais pedagógicos adequados e, em alguns casos, a não legitimidade junto à própria comunidade escolar.

Nessa linha de argumentos, vale lembrar que a formação inicial de professores de Educação Física ainda se dá, numa perspectiva acrítica, com ênfase na formação esportiva, visando o desenvolvimento técnico dos mais habilidosos (DARIDO, 2008).

\section{A proposta, interesses e procedimentos adotados}

$\mathrm{O}$ interesse em propor a referida experiência adveio da demanda surgida pelo cenário atual da Educação Física na escola descrita anteriormente, assim como o envolvimento na área de formação de professores como, por exemplo, atuação como docente do curso de licenciatura em Educação Física, coordenação do Laboratório de Estudos Pedagógicos em Educação Física (LEPEF) e, ainda, integrante do Programa de Pós-Graduação em Educação, na linha de pesquisa "Instituição escolar, formação e profissão docente" do Instituto de Ciências Humanas e Sociais da Universidade Federal de Ouro Preto, MG. Além disso, em virtude da forma como ainda se encontra estruturada a matriz curricular do curso de licenciatura em Educação Física da Universidade Federal de Ouro Preto, que, em decorrência da existência de disciplinas do núcleo comum aos cursos de bacharelado e licenciatura, acaba por restringir, para além dos Estágios Supervisionados, o número de disciplinas que possam propiciar aos acadêmicos momentos vivenciais no ambiente da escola que visem a articulação de saberes específicos para a ação pedagógica.

Dentre as disciplinas de cunho didáticopedagógico constantes na matriz curricular, a "Didática da Educação Física", de caráter eminentemente teórico, localiza-se no quinto período do curso e ocupa um espaço considerável na licenciatura, haja vista que a mesma concentra as seguintes unidades: didática geral e sua interface com a Educação Física, bem como as concepções metodológicas para o ensino da Educação, Física nas quais se incluem aquelas pertencentes aos grupos das propositivas (sistematizadas e não sistematizadas) e as não propositivas (BRACHT, 1999).

Foi observada uma dissonância entre teoria e prática acerca das diferentes concepções metodológicas para o ensino da Educação Física, trabalhadas na disciplina "Didática da Educação Física" no decurso da formação inicial. Em que pese a importância da associação entre teoria e prática, em tese, o Estágio Curricular configura-se como o momento por excelência em que esses alunos pudessem concretizar tal ação. No entanto, a estruturação dos Estágios Curriculares desenvolvidos nos cursos de licenciatura somatiza inúmeras deficiências, que não mais garantem aos futuros professores oportunidade de intervir na realidade social em que se encontram as escolas de educação básica (PIMENTA; LIMA, 2012).

Essa situação, que coloca em questionamento a eficácia ou não dos estágios na formação do licenciado no Brasil, foi apontada por Menga Lüdke ainda no final da década de 1980. A autora denunciou como individualista o caráter da relação que se estabelece entre o aluno estagiário e o profissional que assume o papel de supervisor de campo. Isso porque o estagiário recebe muito pouca ajuda e orientação do supervisor, inexistindo assim uma relação direta que possa favorecer $o$ treinamento e a prática do futuro professor (LÜDKE, 2011). 
Certamente o aprendizado do trabalho no magistério não se limita à formação acadêmico profissional para a qual são fornecidos conhecimentos teóricos e técnicas para o exercício da docência. Tardif e Raymond (2000) explicam que, além dos referidos conhecimentos, as experiências práticas com o fazer do próprio trabalho são fundamentais, pois é nesta instância que serão aprendidos e produzidos saberes práticos essenciais ao exercício da prática profissional pelos docentes (em formação ou já formados). Tardif (2002) aponta três vertentes de saberes que alicerçam a formação docente: os disciplinares, os curriculares e os experienciais. Os saberes disciplinares correspondem aos diversos campos de conhecimento e são integrados nas universidades e divididos em forma de disciplinas. Esses saberes são transmitidos como independentes da instituição de ensino e do curso. Trata-se de uma tradição cultural. Os saberes curriculares correspondem à organização e seleção de conteúdos, métodos, estratégias, entre outros, e se apresentam de forma concreta nos programas escolares, ementas de disciplinas os quais, por sua vez, os professores devem saber aplicar no cotidiano do contexto de trabalho; e, por fim, os saberes experienciais que nascem da experiência profissional e são incorporados individualmente.

Considerando essa concepção sobre os saberes que alicerçam a formação do professor, as condições que decorrem a formação inicial da licenciatura em Educação Física, demandam esforços nos cursos de formação inicial para propostas que visem, pelo menos, minimizar tal situação.

Em virtude dessas considerações, foi definida uma proposta que viabilizasse aos acadêmicos do curso de licenciatura experiências de intervenção em Educação Física na escola. Dessa forma, o primeiro passo consistiu na estruturação de uma disciplina de caráter eletiva denominada "Prática pedagógica em Educação Física". Como forma de assegurar uma sequencialidade na aplicação dos pressupostos teóricos acerca das concepções metodológicas trabalhadas, estabeleceuse como pré-requisito para a matrícula na referida disciplina a conclusão da disciplina "Didática em Educação Física". Assim, a turma da disciplina "Prática Pedagógica em Educação Física", na qual foi desenvolvida a proposta em questão, totalizou 11 alunos matriculados no semestre 2014.2.

Dentre as expectativas esperadas com a proposta de experiência se encontravam: a) viabilizar a articulação entre teoria e prática a partir dos pressupostos teóricos relacionados às concepções metodológicas de ensino da Educação
Física diretamente na realidade cotidiana das aulas de Educação Física na escola; b) concretizar uma reflexão teórico-crítica da aplicabilidade das concepções metodológicas de ensino da Educação Física, a partir da elaboração de planos de aula, sua efetivação na realidade concreta da escola, bem como as discussões e avaliação das ações pedagógicas realizadas; c) propiciar envolvendo do acadêmico com o trato dos conteúdos da Educação Física a partir das vivências com as concepções metodológicas, visando possibilidades de sua utilização, após o encerramento da disciplina, em sua prática pedagógica futura.

Após as primeiras aproximações com a escola escolhida e apresentação da proposta e seus objetivos, tornou-se possível a sua sistematização no que será denominado etapas. Portanto, o ponto de partida consistiu numa visita técnica, por parte dos acadêmicos, acompanhados pelo professor da disciplina. A visita objetivou conhecer a escola, suas instalações, os espaços destinados às aulas de Educação Física; contato com o professor da disciplina; levantamento dos conteúdos trabalhados sobre a existência ou não de um planejamento e, com isso, possibilidade de propor conteúdos diferentes daqueles já trabalhados no referido período letivo, bem como informações sobre os alunos das turmas que seriam atendidos, quantidade de alunos por turma, levando-se em consideração a proporção entre meninos e meninas.

Cumpre aqui caracterizar a escola na qual foi desenvolvida a experiência de práticas educativas. Trata-se de uma escola da rede municipal de ensino, localizada na cidade de Ouro Preto, Minas Gerais, em um bairro de periferia. Essa escola atende uma média de 350 alunos subdivididos nos seguimentos da educação infantil, anos iniciais e finais do ensino fundamental nos turnos da manhã e tarde. No turno da manhã concentram-se turmas dos anos finais e, nas tardes, educação infantil e anos iniciais do ensino fundamental. Ao contrário do que se percebe em muitas outras escolas, onde se cultiva uma hierarquização desvelada dos saberes, na referida escola a disciplina Educação Física compartilha com as demais a mesma posição em termos de relevância no processo de formação dos alunos. As aulas práticas são realizadas em um amplo pátio adaptado para essa finalidade nos fundos da escola. Os demais espaços, como biblioteca, sala de jogos, vídeo, são compartilhados com as demais disciplinas. Dois professores (um professor e uma professora) licenciados em Educação Física compõem o quadro efetivo da escola, sendo que a professora que leciona na escola há vinte e dois anos, encontra-se há três anos como bolsista como 
supervisora do Subprojeto Educação Física do Programa Institucional de Bolsa de Iniciação à Docência (PIBID) da Universidade Federal de Ouro Preto.

De posse das informações obtidas a partir da visita técnica, deu-se início aos encontros com a turma, visando sistematizar as ações pedagógicas para o conjunto de procedimentos fariam necessários na efetivação das práticas educativas naquela realidade.

Assim, levando-se em consideração a disponibilidade da maioria dos acadêmicos, optouse por trabalhar com o turno da manhã. Ficou acordado que o trabalho aconteceria uma manhã por semana, nas aulas do primeiro ao terceiro horário (07:00 as 9:30 horas), nas turmas de $6^{\circ}, 8^{\circ}$ e $9^{\circ}$ anos do ensino fundamental II.

Essas turmas, nas quais se adotava o trabalho integrado entre meninos e meninas eram compostas em média de 26 alunos.

O professor responsável pelas aulas na escola, ao tomar conhecimento dos objetivos da proposta, se mostrou extremamente receptivo e se colocou à disposição para auxiliar o grupo. Ele informou a adoção de um planejamento anual e que, naquele momento do semestre letivo, estava por se iniciar os esportes como tema da unidade didática.

Cabe lembrar que o primeiro semestre letivo de 2014 da Universidade Federal de Ouro Preto transcorreu entre os meses de março a julho. Vivia-se uma fase que antecedia o início dos jogos da Copa do Mundo de Futebol. Com isso, buscou-se trabalhar o conteúdo esportes, numa perspectiva que pudesse extrapolar o Futebol como uma modalidade hegemônica na escola (MELLO et al., 2011; MILLEN NETO; FERREIRA; SOARES, 2011).

Considerando-se as características da escola, das turmas e do tempo de que se dispunha, definiram-se no grupo as concepções metodológicas "Saúde Renovada" (NAHAS, 2013) e "Crítico Superadora" (SOARES et al., 1992). A opção por essas duas concepções metodológicas para o ensino da Educação Física se deveu ao fato de se tratar das duas concepções mais abrangentes e, por sua vez, presentes na escola. A "Saúde Renovada" localizase no grupo das propostas metodológicas não críticas e se fundamenta nos aspectos da saúde. Essa concepção metodológica ressalta a importância da Educação Física voltada à saúde, relacionando os conhecimentos práticos e teóricos de atividade física, aptidão física e saúde, para proporcionar ao aluno entendimento dos benefícios da atividade física e adoção de um estilo de vida ativo. Já a "Crítico Superadora" localiza-se no grupo das progressistas críticas e se fundamenta no materialismo histórico dialético. Trata-se de uma concepção metodológica que entende ser o conhecimento elemento de mediação entre o aluno e o seu apreender (no sentido de construir, demonstrar, compreender e explicar para poder intervir) da realidade social complexa em que vive (SOARES et al., 1992).

Torna-se relevante desenvolver as práticas educativas com intervenções norteadas a partir da singularidade e especificidades de uma proposta crítica e não crítica, haja vista a dificuldade que o acadêmico, geralmente, manifesta em idealizar a efetivação dessas concepções metodológicas na realidade concreta das aulas de Educação Física na escola.

Assim, foi retomado o estudo da primeira concepção metodológica "Saúde Renovada", por meio de leituras de artigos e capítulos de livros, somado a discussões na sala de aula. Na sequência, tendo em vista as características das turmas, deu-se início à fase de elaboração dos planos de aula. As aulas teóricas ganharam a estruturação de oficinas. Nesse ambiente, era possibilitado aos acadêmicos trazer para a sala o referencial teórico utilizado nas discussões iniciais, bem como material para escrita e/ou notebooks. Nessa fase, foi levantada a necessidade da utilização de materiais pedagógicos da universidade para o trato com determinados conteúdos, haja vista que a escola não dispunha de muitos materiais. Foi adotado um modelo padrão de plano de aula no qual se incluía objetivos específicos a partir das dimensões do conteúdo. Dessa forma, para cada aula elaborada se fazia necessário definir, no mínimo, um objetivo conceitual, procedimental e conceitual. Para o trabalho com a referida concepção metodológica, cada acadêmico ficaria responsável por 3 aulas com a mesma turma. A definição das turmas por acadêmico se deu a partir de sorteio. Para todas as intervenções, o acadêmico deveria apresentar no início da mesma a versão final autorizada pelo professor do plano de aula em 3 vias impressas que se destinam ao professor da disciplina "Prática Pedagógica em Educação Física", ao professor responsável pela aulas na escola e, finalmente, uma via para o próprio acadêmico, na condução de sua aula. Para viabilizar a interação dos integrantes da turma, foi estruturada uma lista com os endereços de e-mails pessoais dos acadêmicos, por meio dos quais eram encaminhados materiais para leitura e informativos gerais. Geralmente, dias antes da aula, os planos eram compartilhados entre os integrantes da turma.

Cabe ressaltar que os procedimentos descritos para o trato com a concepção metodológica "Saúde Renovada" se repetiram para a segunda, ou seja, a "Crítico Superadora". 
Foi estruturado um modelo de relatório de observação para os acadêmicos que se encontrassem a observar a aula do colega juntamente com os professores presentes. Apenas o acadêmico que se encontrava a lecionar a sua aula estava, naquele momento, dispensado de fazer as observações e registro. Basicamente, o relatório de observação apresentava aspectos, eventos ou condutas a serem observadas e registradas: estratégias utilizadas em aula visando à participação dos alunos às atividades propostas; voz de comando; postura acadêmica; adequação metodológica de acordo com a faixa etária; eventos que, por ventura, influenciaram o ambiente de aula.

Ainda nessa fase, foram ressaltadas informações relacionadas à conduta dos acadêmicos no ambiente da escola, com ênfase no trato com os alunos. Foram abordados aspectos como a observância de vestimenta adequada e coerente para o ambiente da escola, a postura acadêmica, o emprego de linguagem formal, técnica, cordial e adequada nas aulas, bem como na importância da pontualidade e comprometimento para com as ações pedagógicas que estavam prestes a iniciar naquela escola. Enfim, buscava-se, na medida do possível, não alterar a rotina da escola e sim adaptar-se a ela. Essa fase compreendeu 3 semanas.

Até aqui se buscou relatar a fase de sistematização de procedimentos e ações das práticas educativas. A partir deste ponto, será descrita a experiência na escola.

\section{As práticas educativas}

Geralmente, os acadêmicos chegavam à escola por volta das 06:50 horas da manhã. Nesse espaço de tempo, se organizava o material para a aula que iria acontecer na sala de vídeo ou no pátio. As 6:55 horas realizava-se a acolhida dos alunos, que eram encaminhados pelos professores, em filas, para as respectivas salas de aula.

$\mathrm{O}$ acadêmico responsável pela primeira aula fazia a entrega dos planos de aula aos professores e, na sequência, o encaminhamento da turma até o local da aula. A partir daquele momento, cabia a ele a total responsabilidade pela aula. Apesar de o professor da escola ter se encontrado presente em todas as intervenções, ele foi orientado a não intervir, salvo em casos muito extremos.

Enquanto a aula acontecia, os demais colegas faziam as observações e seus registros. Ao final da terceira aula, que coincidia com o intervalo na escola, era realizado o momento final da prática educativa denominado pelo grupo "momento reflexivo". Para tanto, o grupo se dirigia para a sala de vídeos e lá o professor iniciava com o relato geral da primeira aula. $\mathrm{Na}$ oportunidade, eram levantados aspectos relacionados à concepção metodológica adotada para a aquela aula; à postura do acadêmico na condução da aula; a eventos ocorridos no momento da aula; a possibilidades e situações percebidas; e, ainda, a perspectivas para as próximas aulas. Tudo isso se dava em um ambiente em que se buscava garantir a interlocução de todos: professores, acadêmico responsável pela aula e demais colegas. Esse procedimento se repetia em cada aula realizada naquela manhã. Ao final eram entregues os relatórios da semana anterior, sua revisão e discussão sobre as observações realizadas. Para finalizar, eram recolhidos os relatórios daquela manhã. Essa fase compreendeu 10 semanas.

Por fim, cabe destacar o processo avaliativo adotado para a proposta descrita. Nomeadamente, buscou-se considerar como elementos valorativos as intervenções, os aspectos didático pedagógicos subjacentes às concepções metodológicas adotadas, a qualidade dos planos de aulas, a conduta do acadêmico, a participação e envolvimento nas atividades ao longo das práticas educativas e a pertinência dos textos contidos nos relatórios de observação. O presente critério foi apresentado, discutido e aprovado no grupo na fase que precedeu a visita técnica à escola.

\section{Considerações Finais}

Diante das constatações obtidas ao longo do desenvolvimento da proposta relatada nesse trabalho e considerando possíveis limitações, é possível afirmar que se trata de uma forma de prática educativa que parte dos pressupostos teóricos das concepções metodológicas abordados previamente na disciplina de "Didática da Educação Física". Buscou-se, a partir das vivências nas aulas, não somente a articulação entre teoria e prática, como ainda, a partir das reflexões, inúmeras possibilidades de ação pedagógica no trato dos conteúdos da Educação Física no cotidiano, em situações concretas com alunos e professores reais.

Para além das intenções estabelecidas com a proposta, o relato do professor da escola responsável pelas aulas de Educação Física chamou a atenção do grupo para as inúmeras possibilidades percebidas por ele como implicação direta da experiência sobre sua prática pedagógica.

Nessa direção, promover propostas de práticas educacionais vivenciais para implementar a formação inicial de futuros professores no trato dos conteúdos da Educação Física a partir de efetivação do emprego de concepções metodológicas na educação básica é um esforço que merece ser concretizado. Dessa forma, sugerem-se novas propostas de vivências sobre o tema que possibilitem, sobretudo, o acesso à articulação e apreensão de saberes e seus procedimentos por professores licenciados em Educação Física. 


\section{Referências}

BARBOSA, C. L. A. Situando a Educação Física no contexto escolar. A análise do discurso da Educação Física Escolar. In: Educação Física Escolar as representações sociais. Rio de Janeiro: Shape, 2001. Caps. 1 e 4, p. 21-39; p.81-90.

BRACHT, V. A constituição das teorias pedagógicas da Educação Física. Cadernos Cedes, a. XIX, n. 48, p.69-88, 1999.

BRASIL. Lei 9.394 de 20 de novembro de 1996. Estabelece as diretrizes e bases da educação nacional. $1996 . \quad$ Disponível em: http://www.planalto.gov.br/ccivil_03/Leis/L9394.ht m. Acesso em: 10 jun. 2013.

Lei 9.696 de 01 de setembro de 1998. Dispõe sobre a regulamentação da Profissão de Educação Física e cria os respectivos Conselho Federal e Conselhos Regionais de Educação Física. Brasília: Ministério da Educação, 1998. Disponível em: http://www.planalto.gov.br/ccivil_0 3/Leis/L9696.htm. Acesso em: 10 jun. 2013.

Ministério da Educação/ Conselho Nacional de Educação /Câmara de Educação Superior. Resolução n ${ }^{\circ}$ 7, de 31 de março de 2004. Diretrizes Curriculares Nacionais para os cursos de graduação em Educação Física. Brasília: MEC, 2004. Disponível em: http://portal.mec.gov.br/ cne/arquivos/pdf/ces0704edfisica.pdf. Acesso em: 10 jun. 2013.

DARIDO, S. C. A formação do profissional na Educação Física. Procedimentos, avanços e dificuldades dos professores de Educação Física formados numa perspectiva científica. In: Educação Física na escola: questões e reflexões. Rio de Janeiro: Guanabara Koogan, 2008. Caps. 2 e 4, p. 25-31.

DARIDO, S. C.; RANGEL, I. C. A. Educação Física na escola: implicações para a prática pedagógica. Rio de Janeiro: Guanabara Koogan, 2005 .

\section{Sobre o autor:}

Jairo Antônio da Paixão: Professor Adjunto da Universidade Federal de Ouro Preto (UFOP). Coordenador do Laboratório de Estudos Pedagógicos em Educação Física (LEPEF). Docente do Programa de Pós-Graduação em Educação do Instituto de Ciências Humanas e Sociais da Universidade Federal de Ouro Preto, MG.
KUNZ, E.; TREBELS, A. H. (Orgs). Educação Física critica-emancipatória: com uma perspectiva da pedagogia alemã do esporte. Ijuí: UNIJUÍ, 2006.

LÜDKE, M. O educador: um profissional? In.: CANDAU, V. M. (Org.). Rumo a uma nova didática. 21. ed. Petrópolis: Vozes, 2011.

MELLO, A. S.; SCHNEIDER, O.; SANTOS, W.; VOTRE, S. J.; FERREIRA NETO, A. Educação Física e esporte: reflexões e ações contemporâneas. Movimento, Porto Alegre, v. 17, n. 02, p. 175-193, abr.jun., 2011.

MILLEN NETO, A. R.; FERREIRA, A. C.; SOARES, A. J. G. Políticas de esporte escolar e a construção social do currículo de Educação Física. Motriz, Rio Claro, v.17 n.3, p.416-423, jul./set., 2011.

NAHAS, M. V. Atividade física, saúde e qualidade de vida: conceitos e sugestões para um estilo de vida ativo. 6. ed. Londrina: Midiograf, 2013.

NEIRA, M. G.; NUNES, L. F. Educação Física, currículo e cultura. São Paulo: Phorte, 2009.

PIMENTA, S. G.; LIMA, M. S. L. Estágio e docência. 7. ed. São Paulo: Cortez, 2012.

SILVA, O. O. N. Licenciatura e Bacharelado em Educação Física: diferenças e semelhanças. Revista Espaço Acadêmico, Maringá, v.1, n. 124, p. 76-84, set., 2011.

SOARES, C. et al. Metodologia do ensino de educação física. São Paulo: Cortez, 1992.

TARDIF, M. Saberes docentes e formação profissional. Petrópolis: Vozes, 2002.

TARDIF, M.; RAYMOND, D. Saberes, tempo e aprendizagem do trabalho no magistério. Revista Educação e Sociedade, Campinas, v. 21, n. 73, p. 209-244, dez., 2000. 